\title{
Effects of Administration of Antioxidants in Acute Intermittent Porphyria $^{1}$ )
}

\author{
Stig Thunell ${ }^{1}$, Dan Andersson ${ }^{2}$, Pauline Harper ${ }^{1}$, Ann Henrichson ${ }^{1}$, Ylva Floderus ${ }^{1}$ and Ulf Lindh $^{3}$ \\ 1 Porphyria Centre Sweden, Stockholm, Sweden \\ 2 Department of Medicine, Södersjukhuset, Stockholm, Sweden \\ 3 Department of Radiation Sciences, Uppsala, Sweden
}

Summary: In order to elucidate the question of free radical involvement in acute porphyric crisis, antioxidants were administered to two acute intermittent porphyria patients with long-standing recurrent attacks. Clinical condition and urinary excretion of porphyrins and porphyrin precursors were monitored before, during and after an eight week therapy with daily doses of vitamin $\mathrm{E}, \boldsymbol{\beta}$-carotene, ascorbic acid, selenium, vitamin $\mathrm{Q}$, acetylcysteine, mannitol and carnitine. Blood cell trace element profiles were followed.

The administration of the compound antioxidant formula was found not to further impair the clinical or biochemical conditions of the patients but the incidence of the recurrent crises or the severity of the symptoms were not positively affected. Aberrant blood cell trace element profiles with increased granulocyte manganese were normalized during treatment, on cessation of the therapy again resuming the abnormal pretreatment patterns, which may suggest an origin in oxidative stress. No correlation was observed between the concentration of granulocyte manganese and the excretion of 5-aminolaevulinic acid. Indications for participation of this porphyrin precursor in a radical generating process leading to generalized mitochondrial superoxide dismutase induction, as conceivably signalled by increased intracellular manganese, were thus not obtained.

The failure to note a clinical response to antioxidant therapy may be due to factors dependent upon dosage of, or interaction between, the antioxidant compounds given, or on restricted bioavailability of the antioxidants at critical anatomical sites, and does not per se invalidate the model of acute porphyria as a hyperoxidative condition.

\section{Introduction}

Acute intermittent porphyria is a hereditary disorder of haem metabolism. The clinical expression is dominated by neurologic disturbances and is strongly dependent on exposition of the patient to external agents and hormonal factors. The molecular background is found in mutations in the gene encoding for porphobilinogen deaminase (EC 4.3.1.8), i. e. the enzyme catalyzing the third dedicated step in haem synthesis. The resulting decrease in catalytic capacity gives rise to a bottleneck in the haem synthetic chain. Increased traffic through the pathway, induced e.g. by acute demands for haem, may overload the porphobilinogen deaminase step and result in deficient clearing of the porphyrin precursors 5 -aminolaevulinate and porphobilinogen (1). Although accumulation of 5-aminolaevulinate, as evidenced by increased urinary excretion of the compound, is also noted in some asymptomatic carriers, it is invariably present in the symptomatic phase of the disease. The same is the case

1) This work was supported by grants from the Karolinska Institute. in hereditary tyrosinaemia and lead intoxication where the excretion in magnitude also parallels the severity of the neuropsychiatric symptoms. In the search for an explanation for porphyric neuropathy interest has therefore focused on this metabolite. Under the assumption that it may be a causative factor in acute porphyria a number of hypotheses have been advanced (2). None of these has yet been verified and the question of the pathogenic significance of 5-aminolaevulinate is still open. In the past few years it has, however, been demonstrated that 5-aminolaevulinic acid after enolization and subsequent iron catalyzed oxidation participates in the formation of reactive oxygen species, and that it may act as a prooxidant in vitro as well as in vivo (for references see $D e$ masi et al. (3)). Signs of oxidative injury in rat brain submitted to treatment with 5 -aminolaevulinate point to this property of the compound as one possible causative factor in the development of neuropathy in acute porphyria (4). Further, in a recent work it has been found that the concentration of granulocyte manganese exhibits a 4-fold increase in carriers of acute intermittent porphyria. This has tentatively been interpreted as due to generalized induction of the manganese-based enzyme 
mitochondrial superoxide dismutase, conceivably in response to augmented generation of free radical species by 5 -aminolaevulinate produced in surplus (5).

The theory of acute porphyria as a hyperoxidative condition is the incitement for the present study. An attempt has thus been made to break long-standing chains of recurrent porphyric attacks in two patients with acute intermittent porphyria by administration of antioxidants.

\section{Materials and Methods}

Design of the study

Two adult carriers of different mutations for acute intermittent porphyria with recurrent porphyric attacks were treated for about eight weeks with antioxidants. They were followed through time with regard to clinical condition, porphyrin and porphyrin precursor excretion and granulocyte, erythrocyte and platelet trace element profiles. Informed consent from the patients was obtained.

\section{Patients}

Patient $F$ is a 41-year-old female with acute intermittent porphyria. Her first porphyric crisis occurred at the age of 22 and was precipitated on start of use of oral contraceptives. Since then she has had attacks yearly, characterized by increased porphyrin precursor excretion, vomiting, abdominal pain, depression and occasional paralyses and hallucinations. During the last three years she has had monthly attacks in a cyclic premenstrual pattern and has been subjected to about forty instances of glucose and haemarginate therapy. During the study her menstrual periods became irregular and finally stopped altogether, and the porphyric attacks recurred every other week.

Patient $M$ is a 43-year-old male with acute intermittent porphyria. After intake of disulphiram (Antabus ${ }^{\circledR}$ ), at the age of 37 , he developed his first porphyric attack, which was accompanied by severe abdominal pains, tetraplegia, respiratory insufficiency and psychotic behaviour. Since then, he has had frequent attacks marked by abdominal pain, during the last year approximately every other week. In all, he has received glucose and haemarginate infusions about sixty times.

\section{Diagnostic procedures}

In both patients the diagnosis of acute porphyria was suggested by a family history of acute porphyria and by the periodic recurrence of neuropsychiatric symptoms accompanied by increased urinary levels of porphobilinogen and 5-aminolaevulinic acid.

In the case of the female patient $(F)$, the diagnosis of acute intermittent porphyria was assessed by the findings of low erythrocyte porphobilinogen deaminase activity, and a $198 \operatorname{Trp} \rightarrow$ stop mutation in the porphobilinogen deaminase gene giving rise to a CRIM-negative condition previously shown to be associated with acute intermittent porphyria (6). The porphobilinogen deaminase gene exon $1,33 \mathrm{G} \rightarrow \mathrm{T}$ mutation assessed in patient $\mathrm{M}$, gives rise to a partial deficiency of the enzyme recognized only in non-erythropoietic cells. In this patient, erythrocyte porphobilinogen deaminase activity thus was within the normal range of values, and the diagnosis of acute intermittent porphyria was based on the previous (7) demonstration of an association between the mutation in question and this form of acute porphyria.

\section{Antioxidant administration}

The following tablets/capsules were given.

Oxigard (ACO, Sweden) contains (one tablet) $D-\alpha$-tocopherol acetate $50 \mathrm{mg}$, ascorbic acid $90 \mathrm{mg}, \beta$-carotene $9 \mathrm{mg}$ and sodium selenite $60 \mu \mathrm{g}$.
Bio-Antioxidant ${ }^{\circledR}$ (Pharma Nord, Stockholm, Sweden) contains (one tablet) $\alpha$-tocopherol acetate $97 \mathrm{mg}$, ascorbic acid $200 \mathrm{mg}, \beta$ carotene $7.5 \mathrm{mg}$, vitamin A $250 \mu \mathrm{g}$, selenium (organic) $60 \mu \mathrm{g}$, vitamin $B_{6} 25 \mathrm{mg}$, vitamin $B_{1} 5 \mathrm{mg}$, niacin $5 \mathrm{mg}$, niacin amide $10 \mathrm{mg}$, pantothenic acid $7.5 \mathrm{mg}$, zinc (organic) $7.5 \mathrm{mg}$, manganese (organic) $2 \mathrm{mg}$, copper (organic) $1 \mathrm{mg}$, vitamin $B_{2} 5 \mathrm{mg}$, vitamin $B_{12}$ $4.5 \mu \mathrm{g}$, folic acid $50 \mu \mathrm{g}$, biotin $100 \mu \mathrm{g}$, vitamin D $2.5 \mu \mathrm{g}$ and magnesium $50 \mathrm{mg}$.

C-Vitamin (ACO Stockholm, Sweden) contains (one tablet) $500 \mathrm{mg}$ ascorbic acid.

Bio-Quinon (Pharma Nord, Stockholm, Sweden) contains (one capsule) 2,3-dimethoxy-5-methyl-6-decaprenyl-1,4-benzoquinone (vitamin Q) $30 \mathrm{mg}$.

Acetyl-Cystein (NM Pharma, Stockholm, Sweden) contains (one tablet) acetylcysteine $200 \mathrm{mg}$ and mannitol $250 \mathrm{mg}$.

Carnitene $^{\circledR}$ (Sigma-Tau) contains (one tablet) carnitine $1 \mathrm{~g}$.

Administration of the tablets started on the second day in the asymptomatic phase after a porphyric attack. The different tablets/ capsules were introduced during a 15-day-period in a day to day sequential manner, starting with Oxigard and $\mathrm{C}$-vitamin days 1-3 and followed by Bio-Quinon, Acetyl-Cysteine and Carnitene ${ }^{\circledR}$ days 4, 6 and 9, respectively. After a period of 16 days (patient M) and 32 days (patient F), Oxigard was switched to Bio-Antioxidant. All the tablets/capsules were given in stepwise increased daily dosages.

The final doses of antioxidants were (Bio-Antioxidant period within brackets): $\alpha$-tocopherol $100 \mathrm{mg} /$ day (194 mg/day); ascorbic acid $2.18 \mathrm{~g} /$ day $(2.40 \mathrm{~g} /$ day $)$ and $\beta$-carotene $18 \mathrm{mg} /$ day $(15 \mathrm{mg} /$ day). The dose of selenium was $120 \mu \mathrm{g} / \mathrm{day}$; ubiquinol $90 \mathrm{mg} / \mathrm{day}$; acetylcysteine $400 \mathrm{mg} /$ day; mannitol $500 \mathrm{mg} /$ day and carnitine $1.5 \mathrm{~g} /$ day. Vitamin $\mathrm{C}$ was taken in four daily doses (morning, lunch, afternoon, evening); Bio-Quinon and Carnitene in three (morning, afternoon, evening); and Oxigard, Acetyl-Cysteine and Bio-Antioxidant in two (morning and evening).

\section{Analytical methods}

Porphobilinogen and 5-aminolaevulinic acid were quantitated in urine by the method of Mauzerall \& Granick (8), after separation by ion exchange chromatography, as described by Davis \& Andelman (9). Urinary porphyrins were isolated by anion exchange chromatography and quantitated by spectrophotometry $(10)$. Concentrations of trace elements in erythrocytes, granulocytes and platelets were determined by the technique of particle-induced X-ray emission, using the Scanning Light Ion Microscope in Uppsala, Sweden (Slim-Up). A complete description of the microscope and its performance characteristics are found elsewhere, as are the procedures for blood sampling, preparation of the cells from venous blood, the sample support technique and the sampling of individual cells for investigation (11). Trace element reference values $(\mu \mathrm{g} / \mathrm{g}$ dry weight, mean \pm SD; males and females) are: Granulocyte Ca 19.8 \pm 4.5 , Mn $1.0 \pm 0.5, \mathrm{Fe} 7.3 \pm 3.2$ and $\mathrm{Zn} 32.8 \pm 12.3$; platelet $\mathrm{Fe} 4.9 \pm 1.2$ and $\mathrm{Zn} 5.8 \pm 2.2$; erythrocyte $\mathrm{Ca} 6.8 \pm 2.8$ and $\mathrm{Zn}$ $26.5 \pm 11.1$.

\section{Assessment of clinical status}

The clinical conditions of the two patients were assessed by using a self-rating scheme every $4-8$ days. The symptom diary was designed on the basis of previous experiences of their symptomatology. They were thus instructed to rate the severity, on a scale of 0 to 5 , of the following symptoms: nausea, vomiting, abdominal pain, pain on breathing, other muscle pain, muscular weakness, and depression.

\section{Biochemical monitoring}

At intervals of 3-6 days, related to the current clinical condition, specimens of morning urine were collected and assayed for 5aminolaevulinic acid, porphobilinogen and porphyrins, the concentrations being related to the creatinine contents of the samples. 
Specific therapy in acute phase

Before, during and after the period of antioxidant administration specific therapy was given in the symptomatic phase. On admission for a porphyric crisis, haemarginate (Normosang ${ }^{\circledR}$, Leiras Oy, Helsinki, Finland) containing $23 \mathrm{~g} / 1$ haematin; $6 \mathrm{ml} / 24$ hours, and glucose, $100 \mathrm{~g} / 1 ; 2000 \mathrm{ml} / 24$ hours, were given. The infusions were administered for periods of 3 to 6 days. As a neuroleptic, dixyrazin (Escucos ${ }^{\circledR}$, VCB Pharma AB, Helsingborg, Sweden) $25 \mathrm{mg} / 8$ hours, was given for 4-6 days. For analgesia, morphine (Morphin Pharmacia, Pharmacia Uppsala, Sweden) $10 \mathrm{~g} / \mathrm{l} ; 30-60 \mathrm{mg} / 24$ hours was individually dosed by intra-abdominal pump. Lactulose (Lactulos Tika, Tika, Lund, Sweden) mixture $670 \mathrm{~g} / 1 ; 13.4 \mathrm{~g} / 24 \mathrm{~h}$ and sodium picosulphate (Laxobera ${ }^{\circledR}$, Ferring, Vanlöse, Denmark) $7.5 \mathrm{~g} / 1 ; 5 \mathrm{mg} / 24$ hours, were given from the first day against obstipation.

\section{Results}

In figure 1 urinary concentrations of porphobilinogen, 5 -aminolaevulinic acid and porphyrins, as well as indices for clinical condition, are plotted against time. In order to emphasize the reproduction, in the present study, of a previous (5) observation in porphyria of increased or upper borderline values for some of the elements, as well as the normalization seen during antioxidant therapy, the elemental concentrations are given in percent of upper reference value ("Material and Methods"). In the case of the female patient, the menstrual periods are indicated in the figure. Arrows show when specific 3-4 day therapy was started because of acute porphyric crises ("Material and Methods"). Vertical dotted lines indicate the start and end of antioxidant administration.

As indicated by the biochemical and clinical variables monitored, neither the incidence of porphyric crises, nor the severity of the attacks were affected by the antioxidants given.

Before the start of antioxidant administration, high granulocyte manganese, and high granulocyte and erythrocyte calcium levels, were noted in both patients. Platelet iron values were in the upper reference range. The concentrations of the elements were not found to vary with the current clinical activity of the disease and were shown not to be dependent on the specific therapeutic measures taken during the acute attacks ("Material and Methods"). Nor did they follow the excretion patterns of porphyrins or porphyrin precursors.

Within 3 weeks after the onset of antioxidant treatment, normalization of the increased concentrations of granulocyte manganese, as well as of granulocyte and erythrocyte calcium, were noted in both patients. Other trace elements also took part in the reaction. Granulocyte manganese, calcium, magnesium and iron thus covariated (tab. 1). The pattern also included platelet iron and erythrocyte calcium. Zinc concentrations showed an inverse relation to these elements in all three types of cells studied. The replacement of Oxigard by Bio-Antioxi- dant ("Material and Methods") did not affect the values. The concentrations of the blood cell trace elements about six months after cessation of the antioxidant administration showed returns to pretreatment levels in both patients.

\section{Discussion}

The study was undertaken on the assumption that breaks in the two patients' long standing chains of porphyric attacks, induced by administration of antioxidants, would point to symptomatic acute intermittent porphyria as a hyperoxidative condition and indicate a therapeutic option. The patients were not willing to submit to cerebrospinal fluid sampling and since the source for damaging reactive oxygen species would be 5-aminolaevulinic acid generated within the nervous system, measurements of plasma read-outs for oxidative damage were not attempted. Aminolaevulinic acid is synthesized within the mitochondrion and the primary site, in acute porphyria, for an effective hydroxyl ion attack derived from this compound most probably would be the mitochondrial membrane within cells in the nervous system. Since most intracellular antioxidants are compartmentalized, the lipophilic localization of the alleged radical stress was a prime concern in the design of the antioxidant formula. For theoretical reasons (12), on the basis of observations in recent experimental work (13) and on the, possibly erroneous (vide infra), assumption that antioxidant administration under no circumstances could do the porphyric patient any harm, a compound therapeutic formula was designed. After a period of 16 days and 32 days, respectively, in the two patients, it was supplemented with vitamins of the B-complex, including folate (14) ("Material and Methods"). There is a vast literature regarding the mechanisms underlying the actions of the antioxidants given, and the antioxidant properties of analogues of vitamins $\mathrm{C}$ and $\mathrm{E}$, carotenoids, flavonoids, coenzyme $\mathrm{Q}$, sulphydryl compounds and selenium are well documented in biological systems (15), although not so much in therapeutic use $(12,15)$. Since no reports are available on the substances administered with regard to porphyrinogenicity, the agents were cautiously introduced, and under close clinical and biochemical surveillance of the patients.

As seen in figure 1, the activity of the porphyric disease in the two patients was reflected in their porphyrin precursor excretions. In the female patient, the attacks recurred in periods of 14 days and showed no temporal connection with her menstrual cycle. The porphyric crises in the male patient took place at 10-15 day intervals. The cyclic patterns of the attacks had been virtually the same for several months before the start of the trial, and may reflect therapeutic rebounds connected with recurrent inductions of haem oxygenase in re- 
sponse to the repeated haem infusions. Within two weeks after the start of antioxidant therapy both patients reported feelings of increased vigor and well-being. Neither their clinical condition, nor their porphyrin precursor excretion indicated exacerbations of their porphyric states that could be attributed to the action of substances in the antioxidant formula given. Even in extremely vulnerable porphyric individuals such as the two patients participating in the present study, compound antioxidant therapies of the kinds used thus seem to be without harmful porphyric side-effects.

As previously (5) observed in other individuals carrying the porphobilinogen deaminase gene $198 \operatorname{Trp} \rightarrow$ stop mutation, the female patient before antioxidant treatment had increased levels of granulocyte manganese, as well as of granulocyte and erythrocyte calcium. This

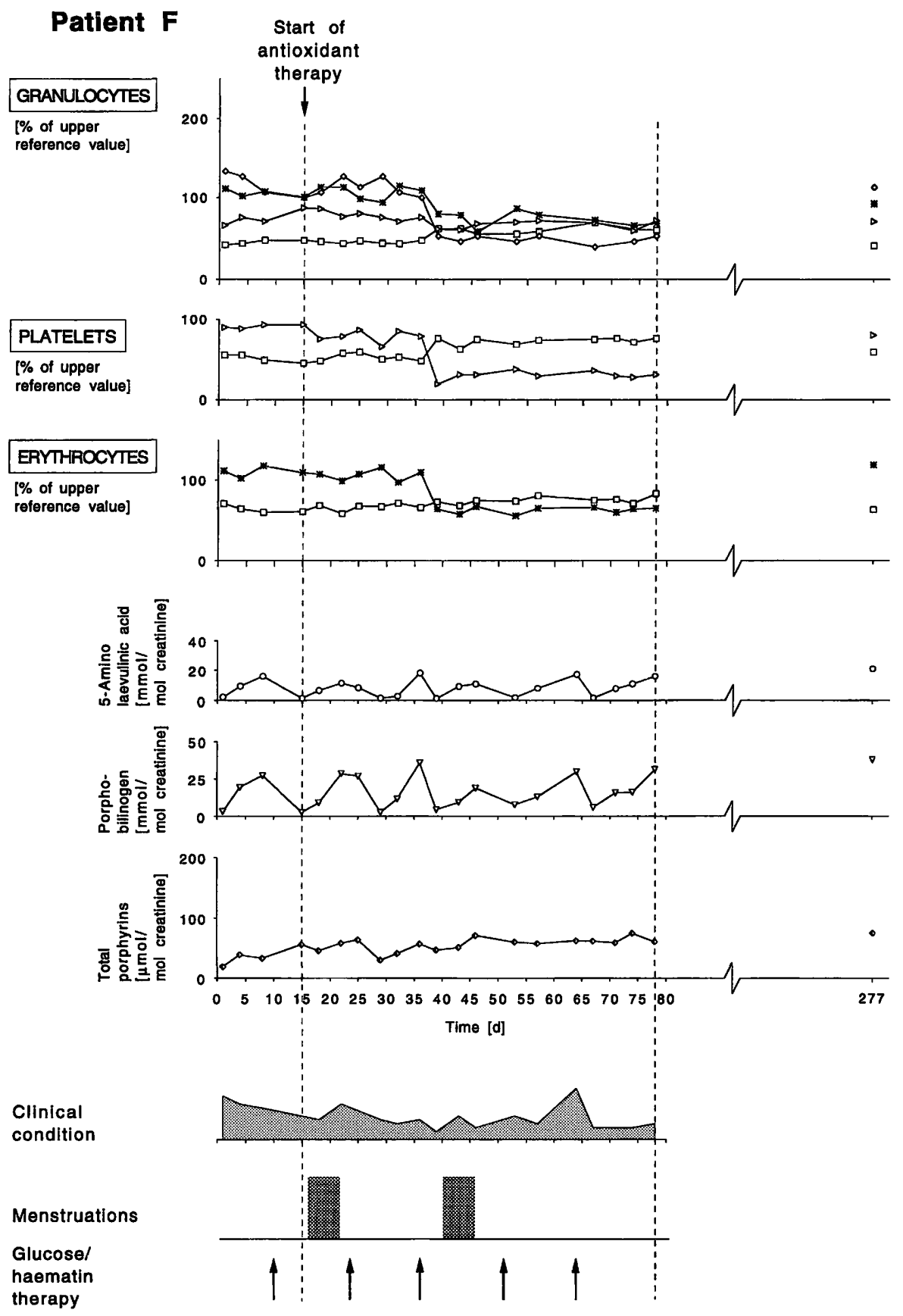

Fig. 1 Clinical conditions, excretions of 5-aminolaevulinic acid, porphobilinogen and porphyrins, and trace element concentrations in granulocytes, platelets and erythrocytes, in the two patients, before, during and after administration of an antioxidant formula.

A female (patient $F$ ) and a male (patient $M$ ) acute intermittent porphyria gene carrier, with recurrent acute attacks, were subjected to an approximately eight week treatment with a compound formula of antioxidants and vitamins ("Material and Methods").
Vertical dotted lines indicate start and end of antioxidant administration. Arrows indicate instances of specific therapy during porphyric crises ("Material and Methods"). In the case of the female patient shaded boxes indicate periods of menstruation.

The trace elements are represented in the figure by the following symbols:

$\mathrm{Ca}(*), \mathrm{Mn}(\diamond), \mathrm{Fe}(\triangleright), \mathrm{Zn}(\square)$. Trace element intracellular concentrations are given in percent of upper reference values (Mean $\pm \mathrm{SD}$; "Material and Methods"). 
pattern was also found in the male patient, who is a carrier of the "Finnish type" exon 1, 33G $\rightarrow \mathrm{T}$ porphobilinogen deaminase gene mutation, demonstrating that this trace element aberration is not coupled to only one of the several mutations producing acute intermittent porphyria. The increase in manganese in granulocytes, a cell type with very active haem synthesis, in a previous work was tentatively interpreted as a marker for a generalized induction of the manganese-associated enzyme mitochondrial dismutase, conceivably due to augmented generation of the superoxide anion radical produced by action of ferrous iron on 5-aminolaevulinic acid (5). On days 14 (patient $M$ ) and 23 (patient F), respectively, after initiation of the antioxidant therapy, the increased concentrations of granulocyte manganese and calcium, as well as of platelet iron and erythrocyte calcium, showed abrupt decreases. The contents of zinc in all three types of cells increased at the same time. The changes in levels of these intracellular elements took place in close concert and also affected the granulocyte levels of magnesium and iron (fig. 1, tab. 1). There is a remarkable congruence in the reaction patterns of the two patients. The fact that the aberrant trace element profile was reproducibly influenced by a therapeutic preparation of antioxidants, and that cessation of antioxidant administration is followed by a reversion to pretreatment levels, may suggest that it had been induced by oxidative stress. The difference in latency of the response between the two patients could in the case be due to differences in pretreatment antioxidant status. On the other hand, no significant positive effects on the incidence of the recurrent porphyric crises, or on the severity of the symptomatology, were noted. Assuming a hyperoxidative origin for the porphyric symptomatology, the

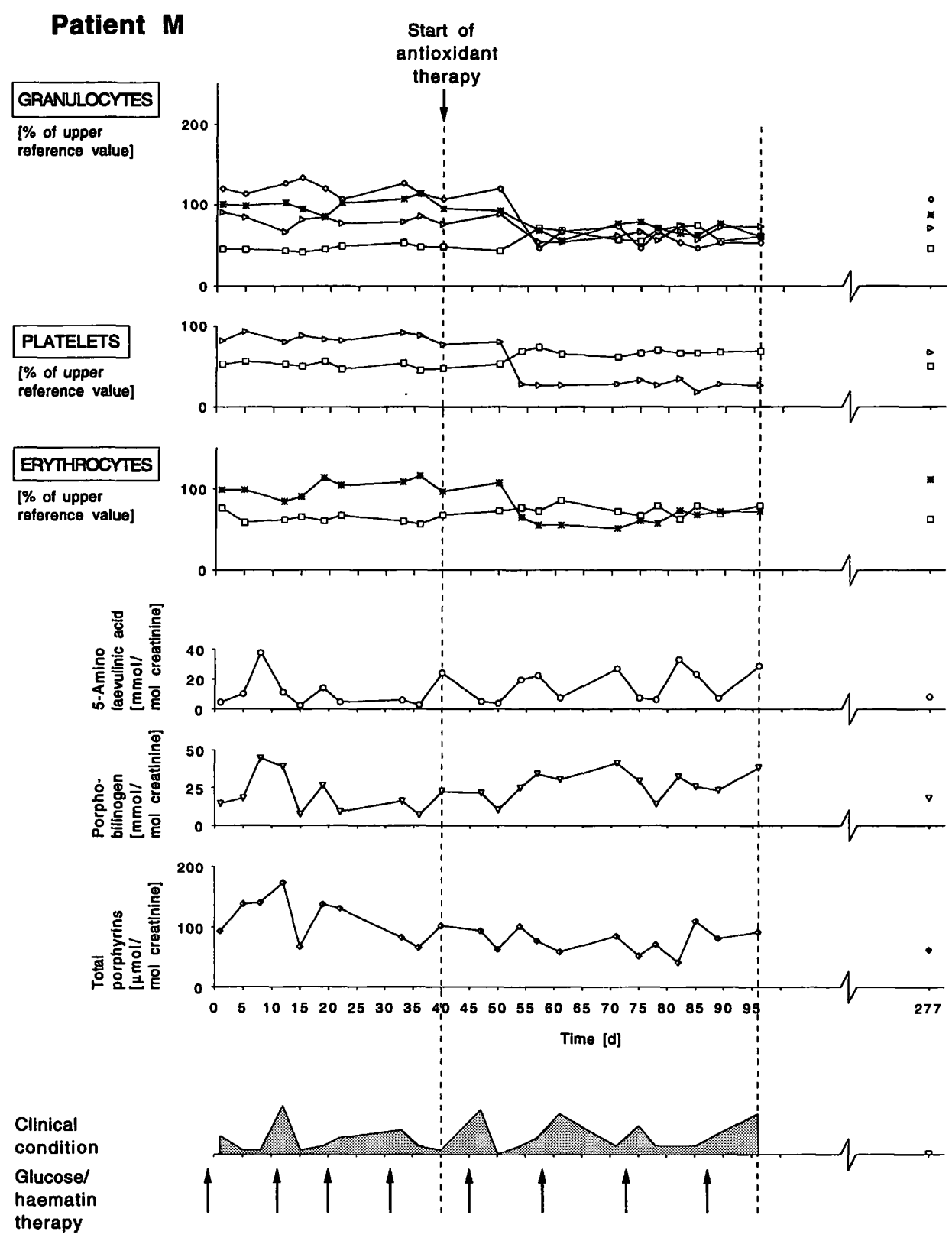

Fig. 1 (Patient M) 
Tab. 1 Blood cell trace elements responding to antioxidant therapy in a male and female patient with acute intermittent porphyria. Correlations with granulocyte manganese.

\begin{tabular}{llrr}
\hline \multirow{2}{*}{ Blood cell type and element } & \multicolumn{2}{l}{ Correlation (r) } \\
\cline { 3 - 4 } & & Female & Male \\
\hline Granulocyte & Granulocyte & & \\
\hline Manganese & Calcium & 0.86 & 0.86 \\
& Iron & 0.56 & 0.72 \\
& Zinc & -0.95 & -0.88 \\
& Magnesium & 0.86 & 0.92 \\
& Platelet & & \\
\cline { 2 - 4 } & Zinc & -0.82 & -0.88 \\
& Iron & 0.91 & 0.97 \\
& Erythrocyte & & \\
\cline { 2 - 4 } & Calcium & 0.93 & 0.83 \\
& Zinc & -0.82 & -0.88 \\
\hline
\end{tabular}

absence of a therapeutic effect could be due to a failure of the administered compounds to reach neurological sites of pathophysiological significance, while they were acting effectively in bioavailable compartments such as blood. Thus, animal experimental models show that even with massive increases in dietary vitamin $\mathrm{E}$ intake, it requires four weeks to achieve significantly elevated antioxidant levels in brain parenchyma (16).

It may thus be that the doses of antioxidants given were insufficient for penetration into the nervous system in amounts to produce clinical effects. The Oxigard administration provided a dose of vitamin $\mathrm{E}$ corresponding to a fivefold increase of Swedish recommendations for the daily intake, and were in accordance with the supplementary doses observed to lower the risks of coronary heart disease and cancer $(17,18)$. The doses administered should also be compared to those given in the antioxidant treatment shown to have a beneficial effect in recurrent pancreatitis (19), where the daily dose of vita$\min \mathrm{E}$ was $189 \mathrm{mg}(270 \mathrm{IU})$ and where $\beta$-carotene 5.4 mg (900 IU), vitamin C $0.54 \mathrm{~g}$, organic selenium 600

\section{References}

1. Kappas A, Sassa S, Galbraith RA, Nordmann Y. The porphyrias. In: Scriver CR, Beaudet AL, Sly WS, Valle D, editors. The metabolic basis of inherited disease. New York: McGrawHill 1995:2103-59.

2. Moore MR, McColl KEL, Rimington C, Goldberg A. Pathogenesis of the neuropathy of acute porphyria. In: Wintrobe MM, editor. Disorders of porphyrin metabolism. New York and London: Plenum Publishing Corporation 1987:119-37.

3. Demasi M, Penatti CAA, DeLucia R, Bechara EJH. The prooxidant effect of 5-aminolevulinic acid in the brain tissue of rats: implications in neuropsychiatric manifestations in porphyrias. Free Radic Biol Med 1996; 20:291-9. $\mu \mathrm{g}$ and methionine $2 \mathrm{~g}$, were given in addition. It is noteworthy that the contents of vitamin $E, \beta$-carotene and selenium in that formula were considerably higher than those used in the present study. Thus it cannot be excluded that a therapeutic effect would have been attained by use of higher doses. Concerning other antioxidants and other disease states, no controlled therapeutic trials have been conducted that can serve as a guide to evaluate the present results.

The protective capacity of an antioxidant system most probably depends on a fine balance between its components. The failure of antioxidant administration to improve the clinical condition in acute porphyria in the present study could thus alternatively be dependent on insufficient attention being paid to the strong pro-oxidant nature of ferrous and cuprous ions, and that components, i. e. ascorbate and cysteine, favoring the generation such of reduced ion species were included in high doses in the formulas administered. This would be a circumstance of extra significance in individuals such as the two participating in the study, probably burdened with a high hepatic iron load resulting from the many haem infusions received.

The two patients engaged in the trial were selected on the basis of the fact that their regularly recurring porphyric crises permitted their use as own controls. Because of difficulties enrolling individuals with such attack patterns in any number, the obvious advantages of this approach are, however, partly counterbalanced by the problem of assessing statistical significance to findings from only two patients. Further, it is by no means given that the studied cases, with their probable haem oxygenase driven pathophysiology, are representative for more common forms of porphyric crises, with sporadic occurrence and with precipitating factors perhaps acting through other inductive mechanisms. In view of the increasing insight into the possible role of free radicals in porphyric illness, an expanded antioxidant study including a larger number of patients as well as patients with other attack patterns, and perhaps using a therapeutic formula containing less reducing substances, might be rewarding.

4. Juknat AA, Kotler ML, Batlle AMC. High $\delta$-aminolevulinic acid uptake in rat cerebral cortex: effect on porphyrin biosynthesis. Comp Biochem Physiol 1995; 111C:143-50.

5. Thunell S, Andersson C, Carlmark B, Floderus Y, Grönqvist SO, Harper $P$, et al. Markers for vulnerability in acute porphyria. A hypothesis paper. Eur J Clin Chem Clin Biochem 1995; 33:179-94.

6. Andersson C, Thunell S, Floderus Y, Forsell C, Lundin G, Anvret $M$, et al. Diagnosis of acute intermittent porphyria in Northern Sweden: an evaluation of mutation analysis and biochemical methods. J Int Med 1995; 237:301-8. 
7. Mustajoki P, Tenhunen R. Variant of acute intermittent porphyria with normal erythrocyte uroporphyrinogen-1-synthase activity. Eur J Clin Invest 1995; 15:281-4.

8. Mauzerall D, Granick S. The occurrence and determination of delta-aminolevulinic acid and porphobilinogen in urine. J Biol Chem 1956; 219:435-46.

9. Davis JR, Andelman SL. Urinary delta-aminolevulinic acid (ALA) levels in lead poisoning. I. A modified method for the rapid determination of urinary delta-aminolevulinic acid using disposable ion-exchange chromatograph columns. Arch Environ Health 1967 ; $15: 53-9$.

10. Doss M, Schmidt A. Rapid determination of urinary total porphyrins by ion exchange chromatography. Z Klin Chem Klin Biochem 1971; 9:415-8.

11. Lindh U, Johansson E. Trace-elements determination in individual peripheral blood cells and possible diagnostic applications. Biol Trace Element Res 1987; 12:351-62.

12. Halliwell B, Gutteridge J, Cross C. Free radicals, antioxidants, and human disease: where are we now? J Lab Clin Med 1992; 119:598-620.

13. Hao Chen, Al L. Protection by vitamin E, selenium, trolox C, ascorbic acid palmitate, acetylcysteine, coenzyme $\mathrm{Q}$, betacarotene, canthaxanthin, and (+)-catechin against oxidative damage to liver slices measured by oxidized heme proteins. Free Rad Biol Med 1994; 16:437-44.

14. Wider de Xifra EA, Batlle AM del C, Stella AM, Malamud S. Acute intermittent porphyria - another approach to therapy. Int J Biochem 1980; 12:819-922.
15. Niki E. Antioxidant compounds. In: Davies, editor. Oxidative damage and repair. Chemical biological and medical aspects. New York: Pergamon Press 1991; 57-64.

16. Machlin I, Gabriel E. Kinetics of tissue alpha-tocopherol uptake and depletion following administration of high levels of vitamin E. Ann NY Acad Sci 1982; 393:48-59.

17. Menkes MS, Comstock G, Vuilleumier Helsing KJ, Rider A, Brookmeyer R. Serum beta-carotene, vitamins A and selenium and the risk of lung cancer. N Engl J Med 1986; 315:1250-4.

18. Blot W, Li J-Y, Tailor P, Guo W, Dawsey S, Wang GQ, et al. Nutrition intervention trials in Linxian China: supplementation with specific vitamin/mineral combination, cancer incidence and disease-specific mortality in the general population. J Natl Cancer Inst 1993; 85:1483-92.

19. Uden S, Bilton D, Nathan L, Hunt LP, Mains C, Braganza JM. Antioxidant therapy for recurrent pancreatitis; placebo-controlled trial. Aliment Pharmacol Therap 1990; 4:357-71.

Received January 3/April 17, 1997

Corresponding author: Associate Professor Stig Thunell, Porphyria Centre Sweden, St. Göran's Hospital, S-11281 Stockholm, Sweden.

Fax: 468 6722434, E-mail: stig.thunell@porfyricentrum.pp.se 
